Marquette University

e-Publications@Marquette

$10-1-2015$

\title{
Spinal and Supraspinal Motor Control Predictors of Rate of Torque Development
}

\author{
S. T. Johnson \\ Oregon State University \\ Kristof Kipp \\ Marquette University, kristof.kipp@marquette.edu \\ m. F. Norcross \\ Oregon State University \\ M. A. Hoffman \\ Oregon State University
}

Accepted version. Scandinavian Journal of Medicine and Science in Sports, Vol. 25, No.5 (October 2015): 623-629. DOI. (C) 2014 John Wiley \& Sons. Used with permission.

This is the peer reviewed version of the following article: "Spinal and Supraspinal Motor Control Predictors of Rate of Torque Development," Scandinavian Journal of Medicine and Science in Sports, Vol. 25, No.5 (October 2015): 623-629, which has been published in final form at DOI. This article may be used for non-commercial purposes in accordance With Wiley Terms and Conditions for selfarchiving. 


\title{
Spinal and supraspinal motor control predictors of rate of torque development
}

\author{
S.T. Johnson \\ School of Biological and Population Health Sciences, \\ Oregon State University, \\ Corvallis, $O R$ \\ K. Kipp \\ Department of Physical Therapy, Marquette University, \\ Milwaukee, WI \\ M.F. Norcross \\ School of Biological and Population Health Sciences, \\ Oregon State University, \\ Corvallis, OR \\ M.A. Hoffman \\ School of Biological and Population Health Sciences, \\ Oregon State University, \\ Corvallis, OR
}


Abstract: During explosive movements and potentially injurious situations, the ability to rapidly generate torque is critical. Previous research has suggested that different phases of rate of torque development (RTD) are differentiately controlled. However, the extent to which supraspinal and spinal mechanisms predict RTD at different time intervals is unknown. RTD of the plantarflexors across various phases of contraction (i.e., $0-25,0-50,0-100$, $0-150,0-200$, and $0-250 \mathrm{~ms}$ ) was measured in 37 participants. The following predictor variables were also measured: (a) gain of the resting soleus $\mathrm{H}$ reflex recruitment curve; (b) gain of the resting homonymous post-activation depression recruitment curve; (c) gain of the GABAergic presynaptic inhibition recruitment curve; (d) the level of postsynaptic recurrent inhibition at rest; (e) level of supraspinal drive assessed by measuring $V$ waves; and ( $f$ ) the gain of the resting soleus $M$ wave. Stepwise regression analyses were used to determine which variables significantly predicted allometrically scaled RTD. The analyses indicated that supraspinal drive was the dominant predictor of RTD across all phases. Additionally, recurrent inhibition predicted RTD in all of the time intervals except $0-150 \mathrm{~ms}$. These results demonstrate the importance of supraspinal drive and recurrent inhibition to RTD.

The ability to rapidly activate the neuromuscular system to produce torque is important during both explosive movements and potentially injurious situations when the time to stabilize a joint in response to a perturbation is limited (Aagaard, 2003). Rate of torque development (RTD), defined as the rate of the rise of the torque-time curve, is frequently used to characterize rapid torque production. Despite its functional importance, the underlying physiological mechanisms contributing to RTD are not fully known.

Previous researchers have reported that RTD is influenced by a variety of factors including intrinsic muscle contractile properties (Andersen \& Aagaard, 2006; Andersen et al., 2010), muscle-tendon stiffness (Bojsen-Møller et al., 2005), maximal muscle strength (Andersen \& Aagaard, 2006; Andersen et al., 2010; Tillin et al., 2012), and neural drive (Van Cutsem et al., 1998; Aagaard et al., 2002a; Tillin et al., 2012). Interestingly, it appears these mechanisms differentially contribute depending on the time interval of RTD that is examined (Bojsen-Møller et al., 2005; Andersen \& Aagaard, 2006; Andersen et al., 2010; Tillin et al., 2012). In fact, those studies overwhelmingly suggest that later phase RTD is primarily a factor of maximal muscle strength (Andersen \& Aagaard, 2006; Andersen et al., 2010; Tillin et al., 2012) and to a lesser extent muscle-tendon stiffness (BojsenMøller etal., 2005). Whereas, earlier phase RTD appears to be controlled by different mechanisms than RTD at later time periods. For 
instance, it has been reported that early phase RTD was primarily a factor of twitch torques (Andersen \& Aagaard, 2006) and muscle fiber type (Andersen et al., 2010). More recently, it was reported that the changes in early phase RTD following a 4-week training for explosive torque production was primarily due to enhanced agonist drive, defined as the amount of voluntary torque produced as a proportion of evoked torque produced (Tillin et al., 2012). Although those are informative findings, it does not explain where in the central nervous system those changes are occurring. An examination of the spinal and supraspinal circuitry may provide novel insight into the production of RTD due to the modulatory effects this circuitry has on the activation of the alpha motor neurons (Wolpaw, 2001).

Several lines of evidence suggest contribution of spinal and supraspinal mechanisms to RTD. One study reported that changes in $\mathrm{H}$-reflex amplitude [tested at $20 \%$ of maximal voluntary contraction (MVC)] were correlated with greater RTD, but not maximal torque following a 3-week resistance training program (Holtermann et al., 2007). However, they examined RTD at only 0-300 ms time interval. Additionally, they tested $\mathrm{H}$ reflexes in isolation which only provides a net estimate of motor neuron pool output and cannot fully account for other spinal motor control mechanisms that modulate the motor neuron pool output, such as pre and postsynaptic inhibition (Zehr, 2002). Another study investigated the gain of the $\mathrm{H}$-reflex recruitment curve $\left(H_{\text {slope }} / M_{\text {slope }}\right)$ at both rest and $10 \%$ of MVC before and after a 4week training that increased RTD (Del Balso \& Cafarelli, 2007). They found no change in the $\mathrm{H}$-reflex recruitment curve, but they did report an increase in supraspinal neural drive as measured with $\mathrm{V}$ waves (Del Balso \& Cafarelli, 2007).

Based on the lack of understanding of how spinal control mechanisms contribute to RTD, especially during different time intervals, we measured a unique collection of variables known to modulate motor neuron pool output to determine which of those predict RTD. Specifically, the variables were (a) gain of the resting soleus $\mathrm{H}$-reflex recruitment curve; (b) gain of the resting homonymous post-activation depression (HPAD) recruitment curve; (c) gammaaminobutyric-acid (GABA)ergic presynaptic inhibition recruitment curve; (d) the level of postsynaptic recurrent inhibition at rest; (e) 
level of supraspinal drive ( $V$ waves); and ( $f$ ) the gain of the resting soleus M wave.

\section{Methods}

\section{Participants}

Forty-one participants ( 20 women and 21 men) were recruited to participate in this study. Participants ranged between the ages of 18 and 35 and were required to be physically active for a minimum of 30 min three times a week. Participants were also free from (a) current injury to the back, upper extremity, or lower extremity; (b) lower extremity injury in the past 6 months; and (c) history of lower extremity ligament surgery. To control for potential hormonal influences across the menstrual cycle, women were tested between days 1 and 3 of their menstrual cycle. Data from four participants were unable to be used due to an inability to complete the testing protocol resulting in total sample of 37 participants (18 women and 19 men) in the study ( $23.8 \pm 3.8$ years, $70.18 \pm 13.65 \mathrm{~kg}, 1.72 \pm 0.08 \mathrm{~m})$. Additionally, recurrent inhibition could not be elicited on two participants but those participants remaining data were included. Further, one participant had an HPAD value that was considered an outlier (more than three box lengths from the middle $50 \%$ of the data) and one participant had a GABAergic presynaptic value that was considered an outlier (more than three box lengths from the middle $50 \%$ of the data). In each case, the specific values that were considered outliers were eliminated from the analyses, but all of their remaining data were included in the final model.

\section{Procedures}

Participants read and signed an informed consent approved by the university's institutional review board and completed a health history and training history questionnaire to determine eligibility to participate in the study. Height was obtained using a wall-mounted stadiometer and weight was determined by a standard scale. The dominant leg was used for all testing and was determined by which leg the participant used for the majority of the following tests: (a) kicking 
a ball; (b) recovering from a balance perturbation; and (c) stepping up on a 10-inch box (Hoffman et al., 1998).

\section{Dynamometer positioning}

Participants were seated on the chair of the Biodex System 3 dynamometer (Biodex Medical Systems, Inc, Shirley, New York, USA) in a semi-recumbent position. The knee was flexed to 60 degrees and ankle positioned in anatomical position (90 degrees of plantardorsiflexion and 0 degrees of inversion-eversion). The foot was secured to the ankle attachment foot plate to prevent any movement of the foot from the plate. The non-test leg was in a comfortable, relaxed position with the foot supported. This positioning was used for all subsequent testing.

\section{Electromyography preparation}

The soleus, tibialis anterior, and lateral malleolus were prepared for application of lubricated surface electromyography (EMG) electrodes $(\mathrm{Ag} / \mathrm{AgCl})$. The EMG electrodes over the muscle were placed longitudinally with an interelectrode distance of $3 \mathrm{~cm}$ for each respective muscle, and a single reference electrode was placed on the lateral malleolus. The EMG data were sampled at $2000 \mathrm{~Hz}$ and stored on a personal computer equipped with a Biopac MP100 data collection system (Biopac Systems Inc, Goleta, California, USA).

\section{Stimulating electrode placement}

To elicit the soleus $\mathrm{H}$ reflex, a stimulating electrode $\left(2 \mathrm{~cm}^{2}\right)$ was placed over the tibial nerve in the popliteal fossa for current delivery. A dispersal pad $\left(3 \mathrm{~cm}^{2}\right)$ was placed superior to the patella on the distal thigh. To elicit GABAergic presynaptic inhibition of the soleus, a stimulating electrode $\left(1 \mathrm{~cm}^{2}\right)$ was placed over the common peroneal nerve distal the fibular head for current delivery and a dispersal pad $\left(3 \mathrm{~cm}^{2}\right)$ was placed just anterior to the fibular head. Care was taken in the placement of the electrode over the peroneal nerve to limit stimulation of the peroneal group.

Scandinavian Journal of Medicine and Science in Sports, Vol 25, No. 5 (October 2015): pg. 623-629. DOI. This article is (C) Wiley and permission has been granted for this version to appear in e-Publications@Marquette. Wiley does not grant permission for this article to be further copied/distributed or hosted elsewhere without the express permission from Wiley. 
NOT THE PUBLISHED VERSION; this is the author's final, peer-reviewed manuscript. The published version may be accessed by following the link in the citation at the bottom of the page.

\section{$H$ reflexes}

$\mathrm{H}$ reflex and $\mathrm{M}$ wave recruitment curves for the soleus were measured at rest by stimulating the tibial nerve in the popliteal fossa. Stimulation was produced by a Grass S88 stimulator (Grass Technologies, West Warwick, Rhode Island, USA). A series of increasing intensity electrical stimuli ( 1 ms pulse duration) beginning near the threshold of the $\mathrm{H}$ reflex and continuing to $\mathrm{M}$ max were applied. There was an approximate 10-s interstimulus latency period. To create $\mathrm{H}$ and $\mathrm{M}$ recruitment curves, the peak-to-peak $\mathrm{H}$ reflex and $M$ wave amplitudes were measured and were normalized to $M_{\max }$. Stimulus intensity was normalized to the maximal stimulus. In order to measure the gain of the unconditioned $\mathrm{H}$ reflex and the $\mathrm{M}$ wave, the recruitment curves were imported into a custom LabVIEW (National Instruments Corporation, Austin, Texas, USA) program. A fourth-order polynomial curve was fit to each curve, the curve was then linearly interpolated to 100 data points, and the peak of the first derivative was calculated (Christie et al., 2004) ( Fig. 1). The peak of the first derivative was utilized because it may provide a better approximation of the gain of the sigmoid shaped $\mathrm{H}$-reflex curve than the more traditional least squares regression line (Christie et al., 2004).

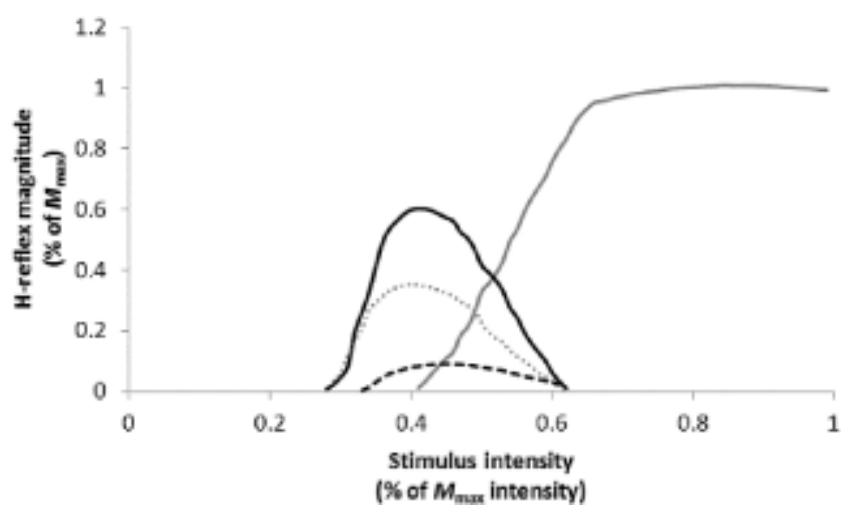

Figure 1. Representative recruitment curve. Solid black line, $\mathrm{H}$ reflex; solid gray line, $M$ wave; dashed (diamonds) gray line, extrinsic presynaptic inhibition; dashed (hash marks) black line, intrinsic presynaptic inhibition.

\section{Presynaptic inhibition}

HPAD is a measure of the relative influence of reflex activation history of the synapse on reflex excitability, functionally acting as a modulator of muscle spindle inflow (Trimble et al., 2000; Earles et al.,

Scandinavian Journal of Medicine and Science in Sports, Vol 25, No. 5 (October 2015): pg. 623-629. DOI. This article is (C) Wiley and permission has been granted for this version to appear in e-Publications@Marquette. Wiley does not grant permission for this article to be further copied/distributed or hosted elsewhere without the express permission from Wiley. 
2002; Kipp et al., 2011). To measure resting HPAD, the paired pulse technique was utilized (Trimble et al., 2000; Earles et al., 2002; Kipp et al., 2011). Two stimuli of the same intensity with a 100-ms interstimulus interval were given to the tibial nerve in the popliteal fossa (Kipp et al., 2011). There was an approximate 10-s interval between each pair of stimulations and the intensity of the stimulations increased from near threshold to $M_{\max }$. The paired stimulation produced two $\mathrm{H}$ reflexes, with the second stimulation typically being depressed relative to the first stimulation. The peak-to-peak amplitudes of the second (i.e., depressed) reflex were determined and normalized to $M_{\max }$, and the stimulus intensity was normalized to the maximum stimulus. A full recruitment curve of the second reflex was obtained, and the gain of the curve was determined using the same procedures previously described for determining the gain of the unconditioned $\mathrm{H}$ reflex and $\mathrm{M}$ wave.

GABAergic presynaptic inhibition reduces the amount of neurotransmitter released from the Ia afferent and is mediated from a variety of sources, including but not limited to peripheral receptors such as antagonistic muscle spindles, cutaneous receptors, and descending supraspinal commands (Pierrot-Deseilligny \& Burke, 2005). To measure resting GABAergic presynaptic inhibition, the $\mathrm{H}$ reflex was conditioned by stimulating the common peroneal nerve (tibialis anterior) $100 \mathrm{~ms}$ prior to stimulating the tibial nerve (soleus). The intensity of the conditioning stimulus was $50 \%$ of the maximal tibialis anterior $\mathrm{M}$ wave. The intensity of the stimulus used to elicit the test reflex followed the same procedure as the $\mathrm{H}$ reflex and paired pulse protocols (i.e., increased from near threshold to $M_{\max }$ ). The peak-topeak amplitudes of the conditioned reflex were normalized to $M_{\max }$, and stimulus intensity was normalized to the maximum stimulus. The gain of the GABAergic presynaptic recruitment curve was determined as previously described for the unconditioned $\mathrm{H}$ reflex, $\mathrm{M}$ waves, and HPAD.

\section{Postsynaptic inhibition}

Recurrent inhibition, a postsynaptic modulator of motor neuron pool output, was measured at rest to assess postsynaptic inhibition (Earles et al., 2002; Knikou, 2008). Two stimulations to the tibial nerve were provided as previously detailed (Pierrot-Deseilligny et al.,

Scandinavian Journal of Medicine and Science in Sports, Vol 25, No. 5 (October 2015): pg. 623-629. DOI. This article is (C) Wiley and permission has been granted for this version to appear in e-Publications@Marquette. Wiley does not grant permission for this article to be further copied/distributed or hosted elsewhere without the express permission from Wiley. 
1976; Knikou, 2008). The first stimulation, $S_{1}$, was set at $25 \%$ of the soleus $M_{\max }$. The second stimulus, $\mathrm{S}_{2}$, was set at $M_{\max }$. Ten trials of $\mathrm{S}_{1}$ alone (i.e., test reflex) and 10 trials of $S_{1}$ followed $10 \mathrm{~ms}$ later by $S_{2}$ (i.e., conditioned reflex) were given. A total of 20 trials were given counterbalanced in pairs. The peak-to-peak amplitudes of the test reflex and the conditioned reflex were measured. The percentage difference between the amplitudes of the two different reflexes was considered the amount of recurrent inhibition, i.e.,

$$
\left(1-\frac{\text { Test Reflex }}{\text { Conditioned Reflex }}\right) \times 100 \%
$$

$R T D$

To determine RTD, participants were instructed to isometrically plantarflex his or her ankle against the foot plate of the dynamometer as fast and hard as possible in response to a light stimulus. The light was attached to the wall $(3 \mathrm{~m})$ in front of the participant. Three trials with 60 -s rest between each trial were performed. The dynamometer was interfaced with the Biopac MP100 data acquisition system and data were sampled at $2000 \mathrm{~Hz}$. The torque-time curves were analyzed using a custom LabVIEW program. The data were first low-pass filtered at $10 \mathrm{~Hz}$ (fourth order, zero phase lag, Butterworth). RTD was calculated by determining the slope of the torque-time curve from the onset of torque production, defined as $2.5 \%$ of peak torque, over the following time intervals: $0-50,0-100,0-150,0-200$, and $0-250 \mathrm{~ms}$. Torque was normalized to mass ${ }^{0.67}$ (Jaric et al., 2005). The average of the three trials for each of the time intervals was used for analysis.

\section{Supraspinal drive}

$\mathrm{V}$ waves, a variant of $\mathrm{H}$ reflexes, were measured to determine the level of supraspinal drive (Gabriel et al., 2006). Participants were instructed to plantarflex as fast and hard as possible following a light stimulus the same as they were during the RTD trials, but once they reached $90 \%$ of their maximum torque, a maximal electrical stimulus (i.e., $M_{\max }$ ) was applied to the tibial nerve (Aagaard et al., 2002b). The threshold for $M_{\max }$ stimulation (i.e., $90 \%$ of peak torque) was calculated from the RTD trials. Five trials of $V$ waves were collected

Scandinavian Journal of Medicine and Science in Sports, Vol 25, No. 5 (October 2015): pg. 623-629. DOI. This article is (C) Wiley and permission has been granted for this version to appear in e-Publications@Marquette. Wiley does not grant permission for this article to be further copied/distributed or hosted elsewhere without the express permission from Wiley. 
NOT THE PUBLISHED VERSION; this is the author's final, peer-reviewed manuscript. The published version may be accessed by following the link in the citation at the bottom of the page.

with 60-s rest between trials. The peak-to-peak amplitude of the $M$ wave and the $\mathrm{V}$ wave were measured and averaged. The ratio of $\mathrm{V}$ wave to $M_{\max }$ was considered the amount of supraspinal efferent neural drive.

\section{Statistical analysis}

Stepwise multiple regression analyses were performed for each of the RTD time intervals (RTD $0-25 \mathrm{~ms}, \mathrm{RTD}_{0-50 \mathrm{~ms}}, \mathrm{RTD}_{0-100 \mathrm{~ms}}, \mathrm{RTD}_{0-150 \mathrm{~ms}}$ $\left.\mathrm{RTD}_{0-200 \mathrm{~ms}}, \mathrm{RTD}_{0-250 \mathrm{~ms}}\right)$. The predictor variables were (a) gain of the resting soleus $\mathrm{H}$-reflex recruitment curve; (b) gain of the HPAD recruitment curve; (c) gain of the GABAergic presynaptic inhibition recruitment curve; (d) the level of postsynaptic recurrent inhibition at rest; (e) level of supraspinal drive ( $V$ waves); and ( $f$ ) the gain of the resting soleus $M$ wave. The probability to enter was set at $\leq 0.05$ and $\geq 0.10$ to remove. All statistical analyses were performed using SPSS 19 (IBM, Armonk, New York, USA).

\section{Results}

Table 1 presents the group means and standard deviations. The results of the regression analysis revealed supraspinal drive as measured by $\mathrm{V}$ waves $\left(\mathrm{V}_{\text {wave }}: M_{\max }\right)$, and resting recurrent inhibition significantly predicted RTD at time intervals less than $100 \mathrm{~ms}$. Specifically, $\mathrm{V}$ waves and recurrent inhibition together explained $34.2 \%(P=0.001)$ of $\mathrm{RTD}_{0-25 \mathrm{~ms}}, 35.8 \%(P=0.002)$ of $\mathrm{RTD}_{0-50 \mathrm{~ms}}$, and $36.8 \%(P=0.001)$ of $\mathrm{RTD}_{0-100 \mathrm{~ms}} \mathrm{~V}$ waves alone were significant predictors of $\mathrm{RTD}_{0-150 \mathrm{~ms}}$ explaining $30.8 \%(P<0.001)$. At the later time intervals, RTD $_{0-200 \mathrm{~ms}}$ and $\mathrm{RTD}_{0-250 \mathrm{~ms}} \mathrm{~V}$ waves and recurrent inhibition were significant predictors with an explained variance of 41.0\% $(P<0.001)$ and 43.0\% $(P<0.001)$, respectively. See Table 2 for regression coefficients.

Table 1. Means and standard deviations for dependent and independent variables

\section{Variable}

Mean values \pm SD

1. RTD, rate of torque development; SD, standard deviation.

$\mathrm{H}$ reflex $(\mathrm{mV} / \mathrm{V})$

Intrinsic presynaptic inhibition $(\mathrm{mV} / \mathrm{V})$
$10.08 \pm 4.15$

$1.97 \pm 1.83$

Scandinavian Journal of Medicine and Science in Sports, Vol 25, No. 5 (October 2015): pg. 623-629. DOI. This article is (C) Wiley and permission has been granted for this version to appear in e-Publications@Marquette. Wiley does not grant permission for this article to be further copied/distributed or hosted elsewhere without the express permission from Wiley. 


\section{Variable}

Extrinsic presynaptic inhibition $(\mathrm{mV} / \mathrm{V})$

Recurrent inhibition (\%)

V wave $\left(\mathrm{V} / \mathrm{M}_{\max }\right)$

M wave $(\mathrm{mV} / \mathrm{V})$

RTD $_{0-25 \mathrm{~ms}}\left[\mathrm{Nm} / \mathrm{s} \cdot\left(\mathrm{kg}^{0.67}\right)^{-1}\right]$

$\mathrm{RTD}_{0-50 \mathrm{~ms}}\left[\mathrm{Nm} / \mathrm{s} \cdot\left(\mathrm{kg}^{0.67}\right)^{-1}\right]$

$\mathrm{RTD}_{0-100 \mathrm{~ms}}\left[\mathrm{Nm} / \mathrm{s} \cdot\left(\mathrm{kg}^{0.67}\right)^{-1}\right]$

$\mathrm{RTD}_{0-150 \mathrm{~ms}}\left[\mathrm{Nm} / \mathrm{s} \cdot\left(\mathrm{kg}^{0.67}\right)^{-1}\right]$

$\mathrm{RTD}_{0-200 \mathrm{~ms}}\left[\mathrm{Nm} / \mathrm{s} \cdot\left(\mathrm{kg}^{0.67}\right)^{-1}\right]$

$\mathrm{RTD}_{0-250 \mathrm{~ms}}\left[\mathrm{Nm} / \mathrm{s} \cdot\left(\mathrm{kg}^{0.67}\right)^{-1}\right]$
Mean values \pm SD

$8.46 \pm 3.73$

$0.77 \pm 0.28$

$0.24 \pm 0.19$

$6.57 \pm 2.05$

$11.80 \pm 4.83$

$15.92 \pm 6.90$

$19.70 \pm 8.62$

$18.16 \pm 7.89$

$15.15 \pm 6.23$

$12.42 \pm 4.98$

Table 2. Regression models with standardized regression coefficients across different time intervals for RTD normalized to body mass ${ }^{0.67}\left[\mathrm{Nm} / \mathrm{s} \cdot\left(\mathrm{kg}^{0.67}\right)^{-1}\right]$

\section{Regression model}

1. ${ }^{a} P<0.05$.

2. ${ }^{b} P \leq 0.01$.

3. ${ }^{c} P \leq 0.001$.

4. RI, recurrent inhibition; RTD, rate of torque development; $\mathrm{V}$ wave, $\mathrm{V}: M_{\max }$ ratio.
$\mathrm{RTD}_{0-25 \mathrm{~ms}}=0.609 \cdot \mathrm{V}$ wavec $+0.388 \cdot \mathrm{RIa}$
$0.342 b$
$\mathrm{RTD}_{0-50 \mathrm{~ms}}=0.619 \cdot \mathrm{V}$ wavec $+0.397 \cdot \mathrm{RIa}$
$0.358 c$
$\mathrm{RTD}_{0-100 \mathrm{~ms}}=0.647 \cdot \mathrm{V}$ wavec $+0.343 \cdot \mathrm{RIa}$
$0.368 \mathrm{c}$
$\mathrm{RTD}_{0-150 \mathrm{~ms}}=0.573 \cdot \mathrm{V}$ wavec
$0.308 \mathrm{c}$
$\mathrm{RTD}_{0-200 \mathrm{~ms}}=0.693 \cdot \mathrm{V}$ wavec $+0.291 \cdot \mathrm{RIa}$
$0.410 c$
$\mathrm{RTD}_{0-250 \mathrm{~ms}}=0.708 \cdot \mathrm{V}$ wavec $+0.290 \cdot \mathrm{RIa}$
$0.430 c$

\section{Discussion}

RTD is important for both injury prevention and explosive movements. However, an understanding of the mechanisms, particularly at the supraspinal and spinal level, contributing to RTD is not complete. Our results suggest that neural drive from supraspinal centers predict RTD regardless of the time period analyzed. Additionally, resting recurrent inhibition - a postsynaptic modulator of motor neuron pool output - was a significant predictor of RTD up to $100 \mathrm{~ms}$ from onset of contraction and during the later time intervals of 0-200 and 0-250 ms. 
NOT THE PUBLISHED VERSION; this is the author's final, peer-reviewed manuscript. The published version may be accessed by following the link in the citation at the bottom of the page.

\section{Supraspinal neural drive and RTD}

Supraspinal neural drive, measured by $V$ waves, was the only variable that significantly predicted RTD during all of the different time periods. Individuals with elevated $\mathrm{V}$ waves also tended to have greater RTD regardless of the time interval examined (see Figs. 2 and 3). The fact that supraspinal drive predicted RTD across all time intervals makes intuitive sense. During activation of the plantarflexors, the soleus motor neurons are facilitated by motor commands from supraspinal centers via the corticospinal tract. Because participants were asked to voluntarily plantarflex as hard and fast as possible against the footplate, this would invoke a motor command from the supraspinal centers.

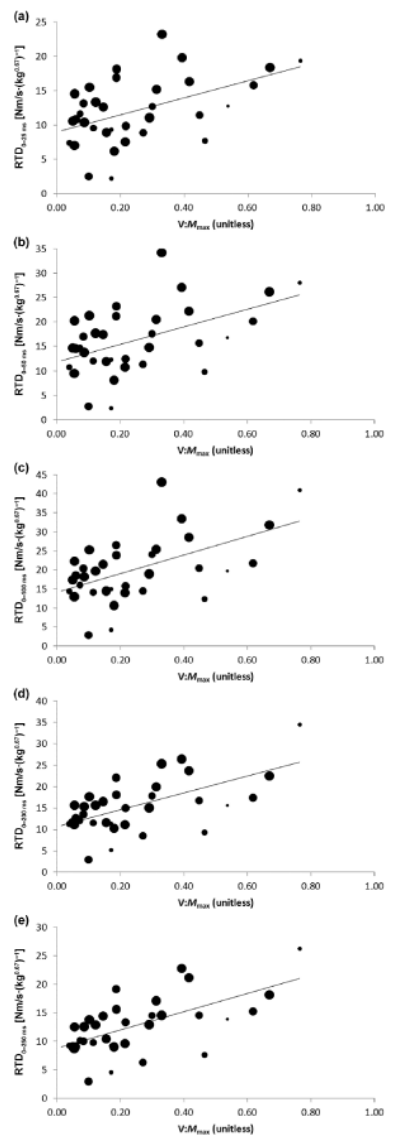

Figure 2. Relation between normalized $\mathrm{V}$-wave magnitude $\left[\mathrm{V}: M_{\max }\right.$ (unitless)] and body mass ${ }^{0.67}$ normalized rate of torque development $\left\{R T D\left[N \mathrm{Nm} / \mathrm{s} \cdot\left(\mathrm{kg}^{0.67}\right)^{-1}\right]\right\} \vee: M_{\max }$ to (a) 0-25 ms (RTD $0-25 \mathrm{~ms})$, (b) 0-50 ms (RTD $0-50 \mathrm{~ms})$, (c) 0-100 ms (RTD $0-100 \mathrm{~ms})$, (d) 0-200 ms (RTD $0-200 \mathrm{~ms})$, and (e) $0-250 \mathrm{~ms}\left(\mathrm{RTD}_{0-250 \mathrm{~ms}}\right.$ ). The size of a dot indicates the magnitude of recurrent inhibition (RI) at rest for a given individual (i.e., a larger dot

Scandinavian Journal of Medicine and Science in Sports, Vol 25, No. 5 (October 2015): pg. 623-629. DOI. This article is (C) Wiley and permission has been granted for this version to appear in e-Publications@Marquette. Wiley does not grant permission for this article to be further copied/distributed or hosted elsewhere without the express permission from Wiley. 
indicates more RI). Note that smaller dots (i.e., individuals with lesser RI) generally fall below the regression line.

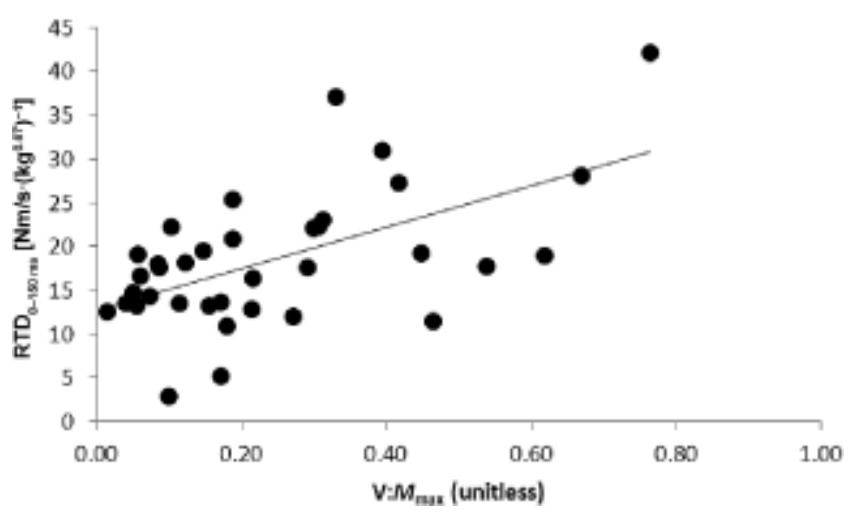

Figure 3. Relation between normalized $\mathrm{V}$-wave magnitude [V: $M_{\max }$ (unitless)] and body mass ${ }^{0.67}$ normalized rate of torque development from 0 to $150 \mathrm{~ms}\left\{\mathrm{RTD}_{0-150 \mathrm{~ms}}\right.$ $\left.\left[\mathrm{Nm} / \mathrm{s} \cdot\left(\mathrm{kg}^{0.67}\right)^{-1}\right]\right\}$.

These results tie in nicely with previous reports of differential contributions to RTD at different time periods. A recent study reported that early phase RTD was primarily a factor of agonist neural drive; however, they did not examine the specific mechanism responsible for the changes but it most likely was due to central factors (Tillin et al., 2012). Additionally, the studies that reported that early phase RTD was primarily a factor of intrinsic muscle properties had explained variances of less than $40 \%$ (Andersen \& Aagaard, 2006; Andersen et al., 2010). This corresponds with the explained variances we found in that same time window (see Table 2). Additionally, it has been reported that maximal muscle strength is the primary contributor to RTD after $100 \mathrm{~ms}$ from onset of contraction, with the explained variances much higher than that reported for earlier phase RTD (Andersen \& Aagaard, 2006). Again our results parallel nicely with those findings because maximal torque production is a by-product of neural drive from the central nervous system and intrinsic muscle characteristics.

Based on our findings it appears that no matter the time interval examined elevated supraspinal spinal drive as measured by $V$ waves are a predictor of greater RTD. These results fit with previous reports of contributors to RTD and are important when developing programs designed to enhance rapid torque production.

Scandinavian Journal of Medicine and Science in Sports, Vol 25, No. 5 (October 2015): pg. 623-629. DOI. This article is (C) Wiley and permission has been granted for this version to appear in e-Publications@Marquette. Wiley does not grant permission for this article to be further copied/distributed or hosted elsewhere without the express permission from Wiley. 
NOT THE PUBLISHED VERSION; this is the author's final, peer-reviewed manuscript. The published version may be accessed by following the link in the citation at the bottom of the page.

\section{Recurrent inhibition and RTD}

Recurrent inhibition measured at rest, along with $\mathrm{V}$ waves, significantly predicted RTD at time intervals up to $100 \mathrm{~ms}$ from onset of contraction and at the later phase time intervals of 0-200 and 0$250 \mathrm{~ms}$. Although recurrent inhibition was a significant predictor at those intervals, the variance recurrent inhibition explained was less than the amount explained by supraspinal drive at each time interval. Despite having a smaller amount of explained variance than $\mathrm{V}$ waves, recurrent inhibition explained over a third of the variance at the 0-25 and $0-50 \mathrm{~ms}$ time intervals, approximately a quarter of the variance at the $0-100 \mathrm{~ms}$ interval, and less than $15 \%$ of the variance at the $0-200$ and $0-250 \mathrm{~ms}$ time intervals. In short, recurrent inhibition predicted more at the earlier time intervals than the later, particularly at the early phase time intervals identified in previous studies (Andersen \& Aagaard, 2006; Andersen et al., 2010; Tillin et al., 2012). Why recurrent inhibition was not a significant predictor to RTD from 0 to $150 \mathrm{~ms}$ is unclear.

Traditionally, it has been thought that greater levels of recurrent inhibition reduces the sensitivity of neurons to changes in excitatory drive and decreases the discharge frequency of the alpha motor neuron (Knikou, 2008). However, recurrent inhibition is not simply a negative feedback loop in that it also synchronizes motor neuron discharges during voluntary contractions (Mattei et al., 2003). Greater motor unit synchronization at the onset of contraction has been proposed to result in a greater RTD (Semmler, 2002). Although our results cannot directly support this, recurrent inhibition does appear to play an important role as a gain regulator of motor neuron pool output (Hultborn \& Pierrot-Deseilligny, 1979).

Although little is known about the relationship between recurrent inhibition and rapid muscle activation, there is evidence that recurrent inhibition is greater in power-trained vs endurance-trained individuals (Earles et al., 2002). Those authors suggested that differences in recurrent inhibition occur because power-trained athletes habitually try to fully activate the motor neuron pool during performance (Earles et al., 2002). Interestingly, a study comparing RTD between explosive-trained athletes and untrained controls found

Scandinavian Journal of Medicine and Science in Sports, Vol 25, No. 5 (October 2015): pg. 623-629. DOI. This article is (C) Wiley and permission has been granted for this version to appear in e-Publications@Marquette. Wiley does not grant permission for this article to be further copied/distributed or hosted elsewhere without the express permission from Wiley. 
greater RTD at $50 \mathrm{~ms}$ in the athletes, but no differences between the groups during RTD at 100 and $150 \mathrm{~ms}$ (Tillin et al., 2010). The fact that the initial $50 \mathrm{~ms}$ of explosive contraction appears to be differentially controlled deserves more research. This early phase RTD is critical in injury situations due to the fact that there is limited time to generate torque to stabilize a perturbed joint. It would be interesting to examine changes in recurrent inhibition and early phase RTD following an intervention designed to increase explosive torque production.

\section{Limitations and future directions}

The current results extend previous reports on the mechanisms underlying the functionally important measure of RTD. Although our study only examined spinal and supraspinal measures, future studies on contributors to RTD should collectively examine factors intrinsic to the muscle, factors that modulate motor neuron pool output, and descending drive from supraspinal centers. By examining these factors in combination, a better understanding how these factors together contribute to rapid torque production can be gained. Additionally, research into the relationship of how both RTD and the spinal and supraspinal variables change in response to different types of resistance training may help guide development of better training regimens for both injury prevention and explosive movements.

A limitation of our study is that we measured spinal motor control of the soleus - a muscle not known for its explosive characteristics. We chose the soleus due to well-established protocols for assessing spinal-level modulation of the soleus motor neuron pool. Our objective was to assess the contribution of a unique collection of spinal and supraspinal variables to RTD. Unfortunately, measures of GABAergic presynaptic inhibition, recurrent inhibition, and $V$ waves of other muscles of the lower extremity considered more functional to explosive movements such as the gastrocnemii and the quadriceps have not been adequately developed.

Another limitation of our study is that we collected all of the spinal-level variables (i.e., H reflex, HPAD, GABAergic presynaptic inhibition, and recurrent inhibition) at rest. It is well known that these measures are context dependent (Zehr, 2002), and the results may not extend to when the muscle is active. Again, our goal was to

Scandinavian Journal of Medicine and Science in Sports, Vol 25, No. 5 (October 2015): pg. 623-629. DOI. This article is (C) Wiley and permission has been granted for this version to appear in e-Publications@Marquette. Wiley does not grant permission for this article to be further copied/distributed or hosted elsewhere without the express permission from Wiley. 
measure a large collection of variables known to modulate motor neuron output and protocols for measuring many of the variables we were interested in during movement are not well established. Although caution is urged in extending these findings to movement, the novel collection of variables collected provides a first step in understanding a first step in understanding the role of supraspinal and spinal mechanisms on rapid torque production. As additional techniques are developed, it may be possible to examine other muscles and movements that are more functional in nature.

\section{Perspectives}

Rapid torque production, particularly during time periods when injuries may occur or explosive movements need to be performed, is critical. The results of this study suggest neural drive from supraspinal centers predicts RTD across all time intervals. Additionally, recurrent inhibition, a postsynaptic modulator of motor neuron pool output, when measured at rest predicts RTD across different time intervals, but more so at earlier time frames. Greater recurrent inhibition has been previously suggested to be different in explosive athletes compared with endurance athletes (Earles et al., 2002). These results suggest that supraspinal and spinal mechanisms when measured at rest predict RTD, but are not the same across all time intervals. Combined with the results of others (Andersen \& Aagaard, 2006; Andersen et al., 2010; Tillin et al., 2012) it appears influences on RTD are multifactorial encompassing neural and muscular elements. Injury prevention programs and training regimens should take this into account because many of these factors may show adaptive plasticity.

\section{Acknowledgements}

Funding was provided by the National Athletic Trainers' Association Research and Education Foundation.

\section{References}

Aagaard P. Training-induced changes in neural function. Exerc Sport Sci Rev 2003: 31: 61-67.

Aagaard P, Simonsen EB, Andersen JL, Magnusson P. Increased rate of force development and neural drive of human skeletal muscle

Scandinavian Journal of Medicine and Science in Sports, Vol 25, No. 5 (October 2015): pg. 623-629. DOI. This article is (C) Wiley and permission has been granted for this version to appear in e-Publications@Marquette. Wiley does not grant permission for this article to be further copied/distributed or hosted elsewhere without the express permission from Wiley. 
following resistance training. J Appl Physiol 2002a: 93: 13181326.

Aagaard $\mathrm{P}$, Simonsen EB, Andersen JL, Magnusson $\mathrm{P}$, Dyhre-Poulsen $\mathrm{P}$. Neural adaptation to resistance training: changes in evoked $\mathrm{V}$ wave and H-reflex responses. J Appl Physiol 2002b: 92: 23092318.

Andersen LL, Aagaard P. Influence of maximal muscle strength and intrinsic muscle contractile properties on contractile rate of force development. Eur J Appl Physiol 2006: 96: 46-52.

Andersen LL, Andersen JL, Zebis MK, Aagaard P. Early and late rate of force development: differential adaptive responses to resistance training? Scand J Med Sci Sport 2010: 20: e162-e169.

Bojsen-Møller J, Magnusson SP, Rasmussen LR, Kjaer M, Aagaard P. Muscle performance during maximal isometric and dynamic contractions is influenced by the stiffness of the tendinous structures. J Appl Physiol 2005: 99: 986-994.

Christie A, Lester S, LaPierre D, Gabriel DA. Reliability of a new measure of H-reflex excitability. Clin Neurophysiol 2004: 115: 116-123.

Del Balso C, Cafarelli E. Adaptations in the activation of human skeletal muscle induced by short-term isometric resistance training. J Appl Physiol 2007: 103: 402-411.

Earles DR, Dierking JT, Robertson CT, Koceja DM. Pre- and postsynaptic control of motoneuron excitability in athletes. Med Sci Sport Exerc 2002: 34: 1766-1772.

Gabriel DA, Kamen G, Frost G. Neural adaptations to resistive exercise: mechanisms and recommendations for training practices. Sport Med 2006: 36: 133-149.

Hoffman MA, Schrader J, Applegate T, Koceja DM. Unilateral postural control of the functionally dominant and nondominant extremities of healthy subjects. J Athl Train 1998: 33: 319-322. Holtermann A, Roeleveld K, Engstrøm M, Sand T. Enhanced H-reflex with resistance training is related to increased rate of force development. Eur J Appl Physiol 2007: 101: 301-312.

Hultborn $\mathrm{H}$, Pierrot-Deseilligny E. Input-output relations in the pathway of recurrent inhibition to motoneurones in the cat. $J$ Physiol 1979: 297: 267-287.

Scandinavian Journal of Medicine and Science in Sports, Vol 25, No. 5 (October 2015): pg. 623-629. DOI. This article is (C) Wiley and permission has been granted for this version to appear in e-Publications@Marquette. Wiley does not grant permission for this article to be further copied/distributed or hosted elsewhere without the express permission from Wiley. 
Jaric S, Mirkov D, Markovic G. Normalizing physical performance tests for body size: a proposal for standardization. J Strength Cond Res 2005: 19: 467-474.

Kipp K, Johnson ST, Doeringer JR, Hoffman MA. Spinal reflex excitability and homosynaptic depression after a bout of wholebody vibration. Muscle Nerve 2011: 43: 259-262.

Knikou M. The H-reflex as a probe: pathways and pitfalls. J Neurosci Methods 2008: 171: 1-12.

Mattei B, Schmied A, Mazzocchio R, Decchi B, Rossi A, Vedel JP. Pharmacologically induced enhancement of recurrent inhibition in humans: effects on motoneurone discharge patterns. $J$ Physiol 2003: 548 (Pt 2): 615-629.

Pierrot-Deseilligny E, Burke DC. The circuitry of the human spinal cord: its role in motor control and movement disorders. 1st edn. Cambridge: Cambridge University Press, 2005.

Pierrot-Deseilligny E, Bussel B, Held JP, Katz R. Excitability of human motoneurones after discharge in a conditioning reflex. Electroencephalogr Clin Neurophsysiol 1976: 40: 279-287.

Semmler JG. Motor unit synchronization and neuromuscular performance. Exerc Sport Sci Rev 2002: 30: 8-14.

Tillin NA, Jimenez-Reyes P, Pain MTG, Folland JP. Neuromuscular performance of explosive power athletes vs untrained individuals. Med Sci Sport Exerc 2010: 42: 781-790.

Tillin NA, Pain MTG, Folland JP. Short-term training for explosive strength causes neural and mechanical adaptations. Exp Physiol 2012: 97: 630-641.

Trimble MH, Du P, Brunt D, Thompson FJ. Modulation of triceps surae $\mathrm{H}$-reflexes as a function of the reflex activation history during standing and stepping. Brain Res 2000: 858: 274-283.

Van Cutsem M, Duchateau J, Hainaut K. Changes in single motor unit behaviour contribute to the increase in contraction speed after dynamic training in humans. J Physiol 1998: 513 (Pt 1): 295305.

Wolpaw JR. Motor neurons and spinal control of movement. Chichester: John Wiley \& Sons, Ltd., 2001.

Zehr EP. Considerations for use of the Hoffmann reflex in exercise studies. Eur J Appl Physiol 2002: 86: 455-468.

Scandinavian Journal of Medicine and Science in Sports, Vol 25, No. 5 (October 2015): pg. 623-629. DOI. This article is (C) Wiley and permission has been granted for this version to appear in e-Publications@Marquette. Wiley does not grant permission for this article to be further copied/distributed or hosted elsewhere without the express permission from Wiley. 